


\section{Internationales Seekriegssrecht.}

Von

\section{Dr. Theodor Niemeyer,}

o. ö. Professor des Internationalen Rechts a. d. Universität Kiel,

Geheimer Justizrat.

Teil I: System des Seekriegsrechtes.

Teil II: Urkundenbuch zum Seekriegsrecht.

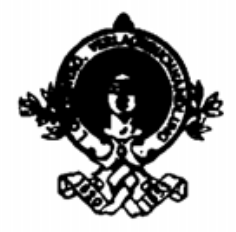

Berlin 1913.

J. Guttentag, Verlagsbuchhandlung, G. m. b. H. 


\section{Urkundenbuch}

\section{znm \\ Seekriegsrecht. \\ Von}

\section{Dr. Theodor Niemeyer,}

o. ö. Professor des Internationalen Rechts a. d. Universität Kiel, Geheimer Justizrat.

(Internationales Seekriegsrecht. Teil II.)

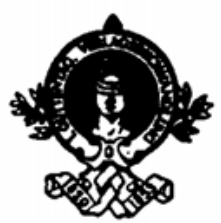

Berlin 1913.

J. Guttentag, Verlagsbuchhandlung, G. m. b. $\mathbf{H}$. 
